\title{
P-1144 - Diabetes Education Beyond Schools: Engaging Students to be Health Advocates for the Community and Raising the Next Generation of Scientists
}

\author{
Faten Sukkar ${ }^{1}$, Zahraa Rahme ${ }^{1}$ \\ ${ }^{1}$ Dasman Diabetes Institute, Education and Training Department, Kuwait
}

\section{Background}

Type 2 diabetes is a chronic disease that is debilitating and is associated with severe complications but is unfortunately perceived as a relatively mild condition. However, Type 2 diabetes is preventable through minor lifestyle modifications. Education through building the understanding of diabetes, mentorship and hands on training, for high school students, to change beliefs and attitudes and promote positive behavior, are highly effective measures to raise awareness and prevent the diabetes epidemic.

The "Let's Stay Healthy, Kuwait" program aimed to educate high school students on topics like the science of diabetes, digestion, nutrition and exercise physiology in a series of workshops to generate an interest in scientific and medical related professions and raise awareness about diabetes.

\section{Aims}

To maximize the benefit of the diabetes awareness program, the students were asked to develop an idea for a civic project that incorporates scientific knowledge gained, to implement at their schools, home, or within the community centered on promoting diabetes awareness and healthy living.

\section{Methods}

The program was designed so that high school students attended a diabetes research institute, for workshops centered on the science of diabetes. The level of scientific information was tailored to suit the age levels of the students and based on what they were learning at schools. A total of 20 schools were hosted during the period from October, 2015 until April 2016. Since, public and private schools participated in the program, there was a need to develop and teach the program in both Arabic and English. The Diabetes Science workshop was adapted from the TEACH project (1) evidence-based educational module about type 2 diabetes prevention. It was intended that the overall program will further help the students to develop an idea for a civic project that they could incorporate at their schools, home, or within the community that was centered on healthy living.

The three fundamental workshops delivered per visit were titled "Diabetes Science", "Digestion and Metabolism", and "Physiology of Exercise". Of the 20 schools that participated in the initiative, 7 were randomly selected to assess the impact of the Diabetes Science workshop. The students were in the age group of 13-18 years old. The maximum number of students per group was 25 . Each workshop in the program was 30 minutes in duration with an added 10 minutes for brainstorming and short activities, and finally 10 minutes for pre and post assessments and evaluation. Additionally, students were presented with an opportunity to participate in an interactive panel discussion with expert researchers to further develop their scientific investigative skills, address their queries and concerns, and to discuss the development of their civic projects.

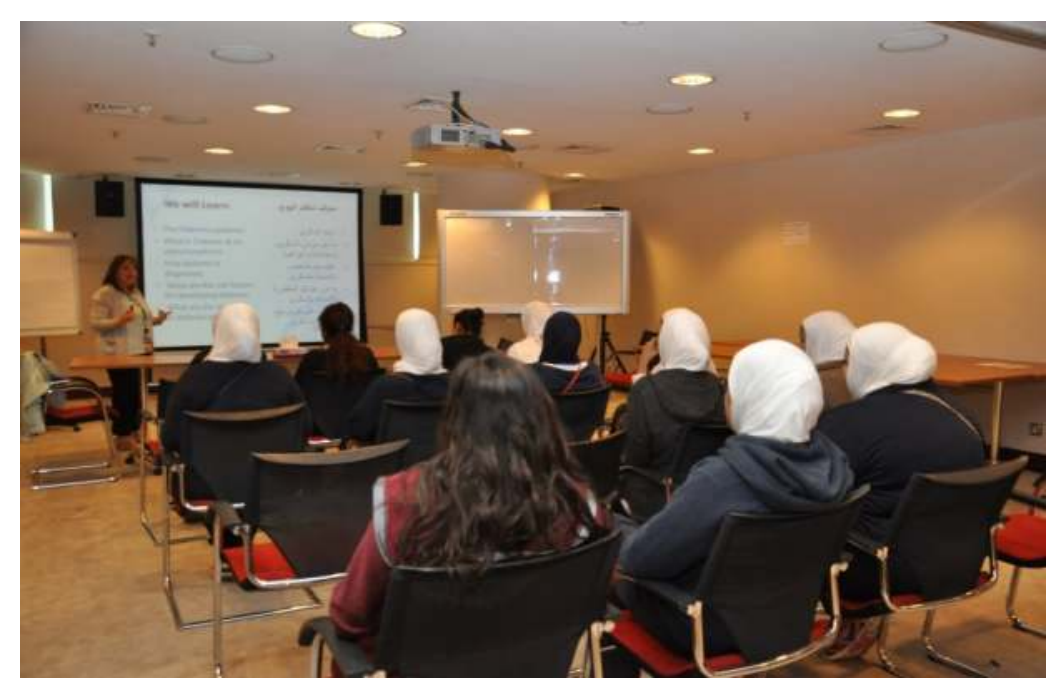

Multiple assessment methods were used to measure the level of knowledge and whether the learning outcomes were achieved. Pre and post assessment quizzes were distributed to all participants at the beginning and end of the Diabetes Science workshop and the program. The assessment consisted of multiple choice questions which were aligned with the intended learning outcomes of the workshop and the entire program.

\section{Results}

A total of 140 students from 7 schools, public and private, participated in this study. In the Diabetes Science workshop, the post-test scores indicated a significant improvement in the diabetes knowledge $(p<0.0001)$ which was a clear indication of the effectiveness of the intervention and that it had met its objectives.

\section{Discussion}

The design of the workshop was successful in generating an interest in the science of diabetes and showed significant improvement in the students' knowledge of diabetes (Figure 1). Additionally, the civic projects that were created, stimulated and engaged their interest in research and the medical related professions. This was evident when the students implemented their projects at schools and advocated healthy lifestyle, through transferring and sharing knowledge with their peers, thus benefitting the entire school community.

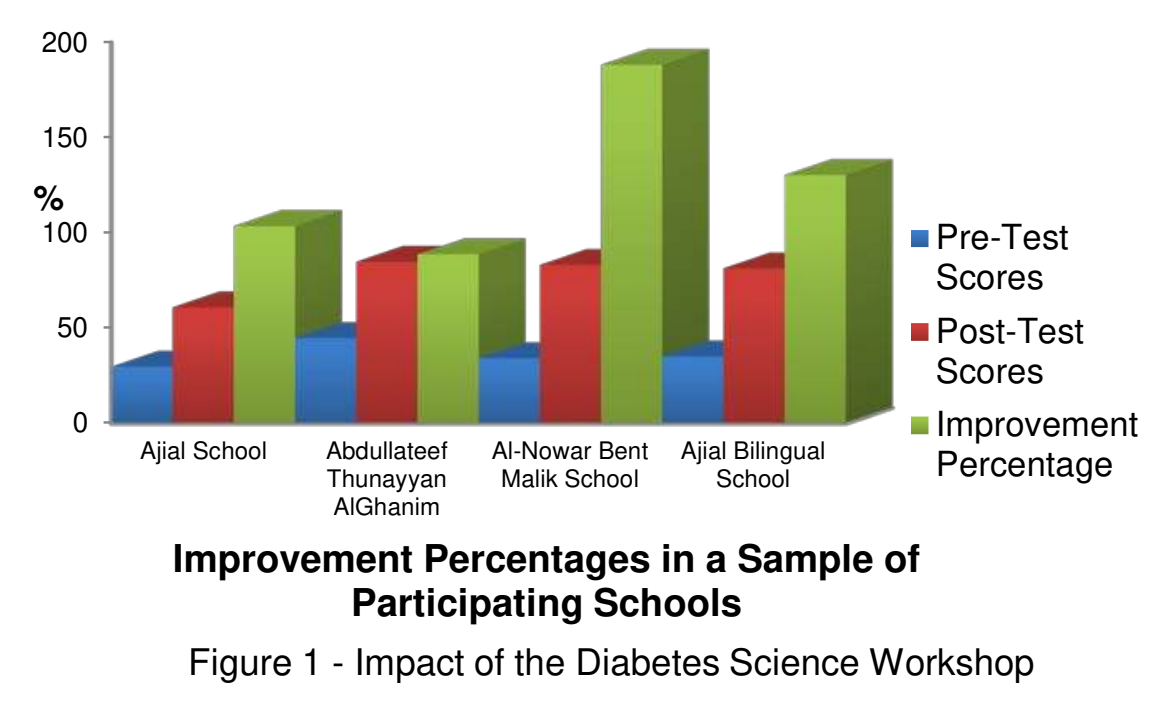

\section{References}

1. (TEACH) TEIACCaH. Diabetes Prevention Toolkit: (C) 2011 Centre for Addiction and Mental Health; [cited 201720 April]. 2011:[Available from: https://www.nicotinedependenceclinic. com/English/teach/Pages/DiabetesPrevention-Toolkit.aspx.

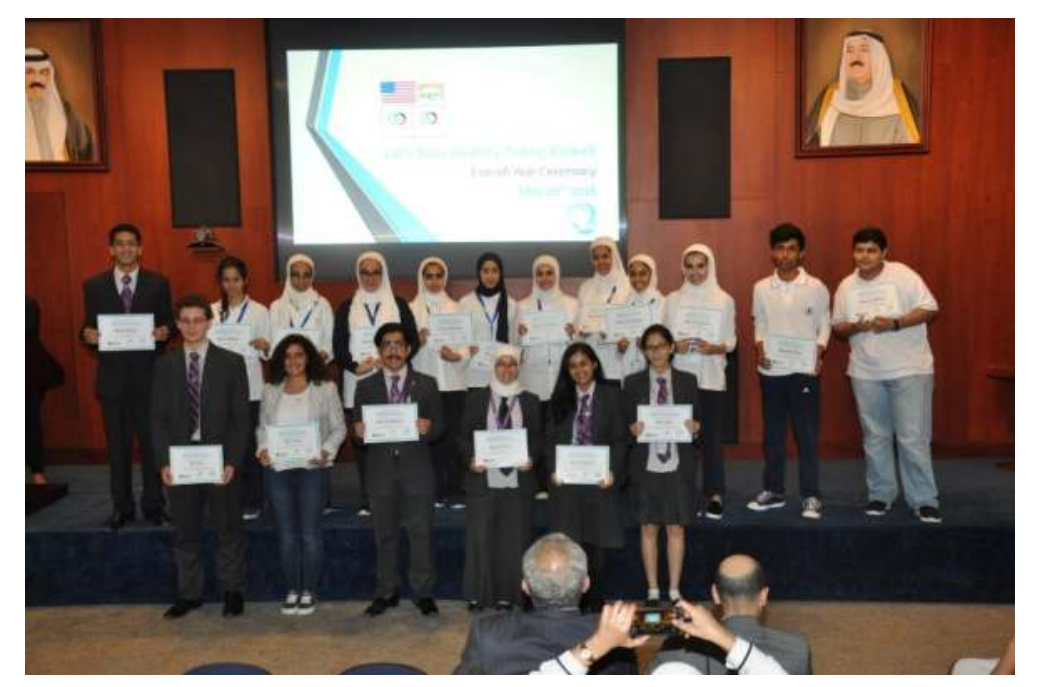

